\title{
MISKONSEPSI SISWA SMA PADA MATERI PERSAMAAN LOGARITMA DENGAN MENGGUNAKAN TES DIAGNOSTIK
}

\author{
Fitri Anggraini ${ }^{1}$, Rizky Oktaviana Eko Putri ${ }^{2}$, Yogie Dana Insani ${ }^{3}$ \\ Universitas Islam Majapahit, Jalan Raya Jabon KM 0.7 Mojokerto \\ ${ }^{1}$ fitrianggraini0203@gmail.com
}

\begin{abstract}
Abstrak
Tujuan dari penelitian ini adalah untuk mendeskripsikan miskonsepsi siswa, penyebab miskonsepsi siswa, dan alternatif dalam menanggulangi miskonsepsi siswa SMA pada materi logaritma dengan menggunakan tes diagnostik. Penelitian ini termasuk kedalam penelitian kualitatif deskriptif. Populasi dalam penelitian ini adalah siswa kelas X MIPA-3. Sampel dalam penelitian ini sebanyak 13 orang. Instrumen yang digunakan dalam pengambilan data adalah berupa angket, tes diagnostik, dan pedoman wawancara. Angket digunakan untuk mengetahui penyebab miskonsepsi siswa. Data tes diagnostik dikumpulkan menggunakan two-tier multiple choice dan three-tier multiple choice untuk mengidentifikasi siswa kedalam paham konsep, miskonsepsi, menebak, pengetahuan lemah, dan tidak paham konsep. Pedoman wawancara digunakan untuk melakukan wawancara hasil tes dan mengetahui sebab miskonsepsi tiap subkonsep materi persamaan logaritma. Berdasarkan hasil penelitian yang diperoleh dari tes diagnostik two-tier multiple choice terhadap siswa kelas X MIPA 3 bahwa miskonsepsi teridentifikasi pada pada nomor 4, 7, dan 10 dengan subkonsep berturut-turut yaitu pada grafik persamaan logaritma, persamaan logaritma berbentuk ${ }^{\mathrm{h}(\mathrm{x})} \log \mathrm{f}(\mathrm{x})={ }^{\mathrm{h}(\mathrm{x})} \log \mathrm{g}(\mathrm{x})$, dan aplikasi logaritma dalam kehidupan. Penyebab miskonsepsi yang dialami oleh siswa pada materi persamaan logaritma menggunakan tes diagnostik Two-Tier dan Three Tier Multiple Choice yaitu miskonsepsi pada nomor 4, 7, dan 10 yaitu karena siswa dan cara mengajar. Alternatif penyelesaian menanggulangi miskonsepsi siswa SMA pada materi logaritma terdapat 2 sebab yakni karena siswa dan karena cara mengajar guru.
\end{abstract}

Kata Kunci: Miskonsepsi, Persamaan Logaritma, Tes Diagnostik

\begin{abstract}
The aim of this study is to describe students' misconception, caused of students' misconception, and how to overcome with alternative solution for students' misconception in senior high school in logarithm equality with diagnostic test. This research is included in qualitative desciptive method. Population of this study is stdents in senior high school grade $\mathrm{X}$ MIPA-3. Sample of this study are 13 students. Instruments which used by this study are questionnaire, diagnostic test, and interview guidelines. Questionnaire is used to know the caused of students' misconception. The result of diagnostic tests are submitted by using two-tier multiple choice dan three-tier multiple choice for identifying the students in scientific knowledge, misconception, guessing, lack of knowledge, and error. Interview guidelines is used to know the result of the tests and cause of misconceptions in every subconcept in logaritm equality. Based of the result from the test of students grade X MIPA 3 that misconcetion identified in number 4,7 , and 10 with eac subconcept in logarithm equality graphic, logarithm equality in ${ }^{\mathrm{h}(\mathrm{x})} \log \mathrm{f}(\mathrm{x})={ }^{\mathrm{h}(\mathrm{x})} \log \mathrm{g}(\mathrm{x})$, and application of logarithm in daily life. Caused of misconception of the students in logarithm equality both using TwoTier dan Three Tier Multiple Choice in number 4, 7, and 10 are because student it self, and teaching method. Alternative solution to overcome misconceptions in senior high school students in logarithm equality are caused by 2 things, student it self and teaching metod.
\end{abstract}

Keywords: Misconception, Logarithm Equality, Diagnostic Test. 


\section{Pendahuluan}

Konsep merupakan salah satu aspek yang terkandung dalam matematika (Murizal, dkk., 2012). Fatqurhohman (2016) mengatakan bahwa salah satu kunci keberhasilan dalam belajar matematika adalah penguasaan konsep. Konsep adalah ide abstrak untuk mengklasifikasikan obyek-obyek sehingga dapat dinyatakan dalam contoh dan bukan contoh (Wafiyah, 2012). Pemahaman pada konsep matematika sangat penting untuk belajar matematika (Utari, dkk., 2012). Pemahaman suatu konsep berarti menguasai elemen pokok konsep, yaitu definisi, ciriciri, dan aplikasi dan dapat menghubungkan serta mengorganisasikan dari apa yang telah dipelajari antara satu dengan yang lainnya (Agustianih, 2017). Dengan pemahaman konsep, siswa diharapkan mampu menggunakan konsep maupun algoritma secara luwes, akurat, efisien, dan tepat dalam pemecahan masalah (Fatqurhohman, 2016). Kurangnya pemahaman konsep matematika dapat menyebabkan miskonsepsi (Herutomo \& Saputro, 2014).

Miskonsepsi adalah kesalahan siswa dalam menangkap konsep awal yang telah diajarkan, sehingga konsep yang diterima tidak sesuai dengan konsep yang sebenarnya (Nakhleh, 1992). Miskonsepsi dapat menimbulkan keprihatinan karena mengarah pada pembentukan konsep dan generalisasi yang salah sehingga menghambat pembelajaran matematika (Leinhardt, dkk., 1990). Sehingga, siswa yang mengalami miskonsepsi akan mengalami kesulitan dan berakibat pada rendahnya hasil belajar siswa (Fitria, 2014). Menurut penelitian yang telah dilakukan oleh Astuti, dkk (2016) faktor penyebab terjadinya miskonsepsi pada siswa adalah kondisi siswa, yang meliputi prakonsepsi yang salah, intuisi yang salah, penalaran yang tidak lengkap, rendahnya kemampuan siswa, dan buku pegangan siswa. Rendahnya kemampuan siswa yang menyebabkan miskonsepsi terjadi pada materi logaritma, yaitu pada menyelesaikan sifat-sifat logaritma (Liang \& Wood, 2005). Allen (2007) mengungkapkan bahwa miskonsepsi siswa terjadi pada persamaan logaritma dengan indikator siswa tidak memeriksa kembali domain pada persamaan logaritma. Berdasarkan silabus matematika kurikulum 2016 edisi revisi, materi logaritma penting dipelajari karena merupakan materi prasyarat untuk mempelajari persamana maupun pertidaksamaan logaritma pada subbab selanjutnya.

Berdasarkan Ekasari (2015) meskipun logaritma merupakan materi yang penting dipelajari, namun siswa masih banyak mengalami kesulitan yang mengakibatkan siswa mengalami kesalahan dan nilai ulangan yang rendah. Berdasarkan penelitiannya yang berjudul “Analisis Kesalahan Siswa Kelas X dalam Menyelesaikan Soal Matematika Pada Materi Logaritma Berdasarkan Prosedur Newman" mengatakan bahwa nilai ulangan pada materi 
logaritma kelas X SMAN 1 Badegan tahun ajaran 2014/2015 masih di bawah KKM yang ditetapkan sekolah yakni 70. Hasil observasi Setiyawan (2016) mengatakan bahwa masih banyak siswa yang masih melakukan kesalahan dalam menyelesaikan soal-soal pada materi logaritma. Hasil wawancara peneliti dengan guru matematika di SMAN I Kutorejo mengatakan bahwa kebanyakan siswa mengalami kesalahan pada sifat-sifat logaritma, pembuatan grafik, dan aplikasi logaritma dalam kehidupan sehari-hari. Dari 5 kelas yang telah diajar, terdapat 3 kelas yang memiliki hasil belajar paling rendah. Hal ini mengindikasikan bahwa materi logaritma masih dianggap sulit bagi siswa. kesulitan tersebut akan menyebabkan kesalahan hingga mengalami miskonsepsi. Berdasarkan nilai hasil ulangan pada materi logaritma masih terdapat lebih dari sebagian siswa tiap kelasnya yang masih mengalami rendahnya hasil belajar. Hasil belajar matematika yang rendah merupakan akibat dari miskonsepsi (Fitria, 2014).

Miskonsepsi perlu adanya penanganan (Fitria, 2014). Purtadi (dalam Fitria, 2014) mengatakan bahwa identifikasi miskonsepsi pentingnya mengidentifikasi miskonsepsi pada siswa dikarenakan konsep-konsep yang salah tersebut akan mengakibatkan siswa mengalami kesalahan untuk konsep pada tingkat berikutnya atau ketidakmampuan menghubungkan antarkonsep. Identifkasi miskonsepsi siswa salah satunya adalah dengan menggunakan tes diagnostik (Muna, 2015). Instrumen diagnostik untuk mengungkap kesulitan siswa dalam mempelajari suatu konsep tertentu dan memberikan petunjuk untuk memecahkan kesulitan yang dimiliki oleh siswa (Suwarto, 2013). Tes diagnostik dapat berupa, tes multiple choice dengan reasoning terbuka, tes multiple choice dengan alasan yang sudah ditentukan dan tes esai tertulis (Susanti, dkk., 2014). Berdasarkan uraian di atas, tujuan penelitian ini adalah mendeskripsikan miskonsepsi siswa, penyebab miskonsepsi siswa, dan alternatif dalam menanggulangi miskonsepsi siswa SMA pada materi logaritma dengan menggunakan tes diagnostik.

\section{Metode Penelitian}

Jenis penelitian ini adalah penelitian deskriptif-kualitatif. Subjek penelitian ini adalah siswa kelas X MIPA SMAN 1 Kutorejo. Satu kelas dipilih sebagai subjek penelitian dengan rekomendasi dari guru matematika dengan kelas yang paling banyak mengalami miskonsepsi saat belajar materi logaritma yang didukung dengan nilai siswa selama belajar logaritma. Instrumen utama dalam penelitian ini adalah peneliti itu sendiri. . Instrumen pendukung dalam penelitian ini adalah lembar soal tes (Two-Tier Multiple Choice dan Three Tier Multiple Choice), lembar angket, dan pedoman wawancara. Pemeriksaan keabsahan data dalam penelitian ini adalah dengan melakukan triangulasi. Triangulasi yang dipakai adalah triangulasi 
metode dengan menggunakan triangulasi tes dan tes. Peneliti membandingkan data yang diperoleh hasil miskonsepsi tahap I dan hasil miskonsepsi tahap II apakah terdapat kekonsistenan atau tidak. Jika valid, maka data hasil miskonsepsi I dan data hasil miskonsepsi II mengalami kekonsistenan. Namun jika tidak terdapat kekonsistenan, maka akan dilakukan pemberian tes ulang sampai memperoleh data yang valid.

Pengelompokan data hasil tes Two-Tier Multiple Choice (tes I) adalah dengan menganalisis hasil tes siswa kemudian akan dikelompokkan berdasarkan kriteria yang diadopsi dari Salirawati (2011).

Tabel 1 Tipe Respon Jawaban Tes I

\begin{tabular}{ccc}
\hline No & Pola Jawaban Siswa & Kategori Tingkat Pemahaman \\
\hline $\mathbf{1}$ & Jawaban inti tes benar-alasan benar & Memahami (M) \\
\hline $\mathbf{2}$ & Jawaban inti tes benar-alasan salah & Miskonsepsi (Mi) \\
\hline $\mathbf{3}$ & Jawaban inti tes salah-alasan benar & Miskonsepsi (Mi) \\
\hline $\mathbf{4}$ & Jawaban inti tes salah-alasan salah & Tidak Memahami (TP) \\
\hline
\end{tabular}

Sedangkan pengelompokan data hasil tes Three-Tier Multiple Choice (tes II) adalah dengan menganalisis hasil tes siswa kemudian akan dikelompokkan berdasarkan kriteria yang diadaptasi dari Kaltakçı \& Nilüfer (2007), pada Tabel 2

Tabel 2 Tipe Respon Jawaban Hasil Tes II

\begin{tabular}{ccccc} 
No & $\begin{array}{c}\text { Tingkat } \\
\text { I }\end{array}$ & $\begin{array}{c}\text { Tingkat } \\
\text { II }\end{array}$ & Tingkat III & Kategori \\
\hline 1 & Benar & Benar & Yakin & Paham (Scientific Knowledge $)$ \\
\hline 2 & Benar & Benar & Tidak Yakin & $\begin{array}{c}\text { Pengetahuan Lemah (Lack of } \\
\text { Knowledge })\end{array}$ \\
\hline 3 & Salah & Benar & Tidak Yakin & $\begin{array}{c}\text { Pengetahuan Lemah (Lack of } \\
\text { Knowledge) }\end{array}$ \\
\hline 4 & Benar & Salah & Tidak Yakin & $\begin{array}{c}\text { Pengetahuan Lemah (Lack of } \\
\text { Knowledge) }\end{array}$ \\
\hline 5 & Salah & Salah & Tidak Yakin & $\begin{array}{c}\text { Pengetahuan Lemah (Lack of } \\
\text { Knowledge) }\end{array}$ \\
\hline 6 & Salah & Salah & Yakin & Tidak Paham Konsep (Error) \\
\hline 7 & Benar & Salah & Yakin & Miskonsepsi \\
\hline 8 & Salah & Benar & Yakin & Miskonsepsi \\
\hline
\end{tabular}

Data siswa yang didapat berdasarkan Tabel 3.3 akan dikategorikan dalam bentuk persentase data siswa yang memahami, miskonsepsi, dan tidak memahami konsep. Adapun perhitungan data tersebut menggunakan rumus:

$$
p=\frac{f}{N} \times 100 \%
$$




\section{Keterangan:}

$\mathrm{p}=$ angka persentase (per kelompok)

$\mathrm{f}=$ jumlah siswa tiap kelompok dari setiap soal

$\mathrm{N}=$ jumlah siswa yang dijadikan subjek penelitian

Diadaptasi dari Fitria (2014)

Penarikan kesimpulan hasil tes I siswa akan disediakan seperti tabel di bawah ini

Tabel 3 Hasil Miskonsepsi Siswa Tes I

\begin{tabular}{lcccccc}
\hline No & $\begin{array}{c}\text { Sub } \\
\text { Konsep }\end{array}$ & $\begin{array}{c}\text { No. } \\
\text { Soal }\end{array}$ & $\begin{array}{c}\text { Memaha- } \\
\text { mi (B-B) }\end{array}$ & $\begin{array}{c}\text { Miskon- } \\
\text { sepsi (B- }\end{array}$ & $\begin{array}{l}\text { Mene- } \\
\text { bak (S- }\end{array}$ & Tidak Memahami (S-S) (\%) \\
& & $(\%)$ & S) $(\%)$ & B $(\%)$ \\
\hline
\end{tabular}

Diadopsi dari Kurniasih \& Haka (2017)

Penarikan kesimpulan hasil tes I siswa akan disediakan seperti Tabel 4

Tabel 4 Hasil Miskonsepsi Siswa Tes II

\begin{tabular}{ccccc}
\hline No & $\begin{array}{c}\text { Tingkat } \\
\text { I }\end{array}$ & $\begin{array}{c}\text { Tingkat } \\
\text { II }\end{array}$ & $\begin{array}{c}\text { Tingkat } \\
\text { III }\end{array}$ & Kategori \\
\hline 1 & Benar & Benar & Yakin & Paham (Scientific Knowledge $)$ \\
\hline 2 & Benar & Benar & $\begin{array}{c}\text { Tidak } \\
\text { Yakin }\end{array}$ & $\begin{array}{c}\text { Pengetahuan Lemah (Lack of } \\
\text { Knowledge })\end{array}$ \\
\hline 3 & Salah & Benar & $\begin{array}{c}\text { Tidak } \\
\text { Yakin }\end{array}$ & $\begin{array}{c}\text { Pengetahuan Lemah (Lack of } \\
\text { Knowledge })\end{array}$ \\
\hline 4 & Benar & Salah & Tidak & $\begin{array}{c}\text { Pengetahuan Lemah (Lack of } \\
\text { Yakin }\end{array}$ \\
\hline 5 & Salah & Salah & Tidak & Pengetahuan Lemah (Lack of \\
& & & Yakin & Knowledge) \\
\hline 6 & Salah & Salah & Yakin & Tidak Paham Konsep (Error) \\
\hline 7 & Benar & Salah & Yakin & Miskonsepsi \\
\hline 8 & Salah & Benar & Yakin & Miskonsepsi \\
\hline
\end{tabular}

Diadaptasi dari Kaltakçı \& Nilüfer (2007)

Setelah siswa melakukan pengisian angket tentang faktor penyebab miskonsepsi, maka peneliti akan melakukan pengelompokan data siswa berdasarkan hasil yang telah diperoleh. Pengelompokan siswa didasarkan pada faktor miskonsespsi yang mereka isikan pada angket yang telah disediakan oleh peneliti. Pengelompokan siswa akan disediakan dalam bentuk tabel seperti pada Tabel 5: 
Tabel 5 Pengelompokan Angket Siswa

\begin{tabular}{lcc}
\hline No & Pernyataan & \multicolumn{2}{c}{ Banyak Respon Siswa } \\
\cline { 2 - 2 } & & Ya \\
\hline Siswa & \\
\hline Cara Mengajar & \\
\hline Buku Teks & \\
\hline Konteks & \\
\hline
\end{tabular}

Diadaptasi dari Kurniasih \& Haka (2017)

Berdasarkan tabel 5, maka peneliti akan menghitung presentase siswa berdasarkan sebab utama miskonsepsi siswa dengan rumus

$$
p=\frac{f}{N} \times 100 \%
$$

Keterangan:

$\mathrm{p}=$ angka persentase (per kelompok)

$\mathrm{f}=$ jumlah siswa tiap kelompok

$\mathrm{N}=$ jumlah siswa yang dijadikan subjek penelitian

Diadaptasi dari Fitria (2014).

Setelah melakukan perhitungan, maka peneliti akan menyimpulkan banyaknya siswa yang mengalami miskonsepsi berdasarkan sebab miskonsepsi. Kesimpulan dari hasil tes akan disajikan dalam tabel seperti di bawah ini

Tabel 6 Hasil Angket Siswa

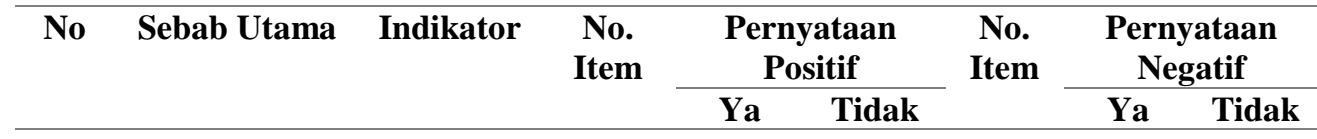

Diadopsi dari Kurniasih \& Haka (2017)

\section{Hasil dan Pembahasan}

Hasil tes

Berdasarkan hasil analisis data, maka hasil kategori untuk tes I (Two-Tier Test) dan Tes II (Three-Tier Test) adalah sebagai berikut: 
Tabel 7 Kategori Subjek Tes I dan Tes II pada Materi Persamaan Logaritma

\begin{tabular}{|c|c|c|c|c|c|}
\hline \multirow[t]{2}{*}{ No } & \multicolumn{2}{|r|}{ Tes I } & \multicolumn{2}{|r|}{ Tes II } & \multirow[t]{2}{*}{ Kesimpulan } \\
\hline & $\begin{array}{l}\text { Nama } \\
\text { Siswa }\end{array}$ & Kategori & $\begin{array}{l}\text { Nama } \\
\text { Siswa }\end{array}$ & Kategori & \\
\hline \multirow[t]{2}{*}{1} & DI & Tidak Paham Konsep & DI & Tidak Paham Konsep & Bukan Miskonsepsi \\
\hline & DA & Menebak & AP & Diam (Menebak) & \\
\hline \multirow[t]{2}{*}{2} & LR & Menebak & - & - & Bukan Miskonsepsi \\
\hline & MA & Tidak Paham Konsep & - & - & \\
\hline \multirow[t]{2}{*}{3} & LR & Menebak & AS & Miskonsepsi & Bukan Miskonsepsi \\
\hline & DI & Tidak Paham Konsep & HM & Pengetahuan Lemah & \\
\hline \multirow[t]{2}{*}{4} & MR & Miskonsepsi & $\mathrm{ES}$ & Menebak & Miskonsepsi \\
\hline & $\mathrm{DA}$ & Menebak & DI & Miskonsepsi & \\
\hline \multirow[t]{2}{*}{5} & $\mathrm{AD}$ & Tidak Paham Konsep & AA & Tidak Paham Konsep & Bukan Miskonsepsi \\
\hline & DI & Tidak Paham Konsep & DA & Miskonsepsi & \\
\hline \multirow[t]{2}{*}{6} & LR & Menebak & DI & Tidak Paham Konsep & Bukan Miskon-sepsi \\
\hline & $\mathrm{AD}$ & Miskonsepsi & ES & $\begin{array}{c}\text { Tidak Bisa Sama } \\
\text { Sekali }\end{array}$ & \\
\hline \multirow[t]{2}{*}{7} & DI & Tidak Paham Konsep & DA & Miskonsepsi & Miskon-sepsi \\
\hline & MS & Miskonsepsi & DI & Tidak Paham Konsep & \\
\hline \multirow[t]{2}{*}{8} & - & - & MR & Tidak Paham Konsep & Bukan Miskon-sepsi \\
\hline & - & - & $\mathrm{ES}$ & - & \\
\hline \multirow[t]{2}{*}{9} & MA & Menebak & ES & - & Bukan Miskon-sepsi \\
\hline & $\mathrm{AD}$ & Tidak Paham Konsep & AS & Tidak Paham Konsep & \\
\hline \multirow[t]{2}{*}{10} & LR & Miskonsepsi & $\mathrm{DA}$ & Miskonsepsi & Miskon-sepsi \\
\hline & DA & Miskonsepsi & YM & Miskonsepsi & \\
\hline
\end{tabular}

Tabel 8 Letak Misonsepsi Pada Materi Persamaan Logaritma

\begin{tabular}{|c|c|c|c|c|}
\hline $\begin{array}{l}\text { Nomor } \\
\text { Soal }\end{array}$ & Subkonsep & $\begin{array}{c}\text { Kode } \\
\text { Subjek }\end{array}$ & Tipe Tes & Letak Miskonsepsi \\
\hline 4 & Grafik persamaan logaritma & MR & $\mathrm{I}$ & $\begin{array}{l}\text { Belum memahami notasi titik } \\
\text { koordinat }\end{array}$ \\
\hline 6 & $\begin{array}{l}\text { Persamaan logaritma berbentuk }{ }^{\mathrm{a}} \log \\
\qquad \mathrm{f}(\mathrm{x})={ }^{\mathrm{a}} \log \mathrm{g}(\mathrm{x})\end{array}$ & $\mathrm{AD}$ & I & $\begin{array}{c}\text { tidak memeriksa kembali } \\
\text { domain pada persamaan } \\
\text { logaritma }\end{array}$ \\
\hline 7 & $\begin{array}{l}\text { Persamaan logaritma berbentuk }{ }^{\mathrm{h}(\mathrm{x})} \log \\
\mathrm{f}(\mathrm{x})={ }^{\mathrm{h}(\mathrm{x})} \log \mathrm{g}(\mathrm{x})\end{array}$ & MS & I & Sifat-sifat logaritma \\
\hline 10 & Aplikasi logaritma dalam kehidupan & DA & $\mathrm{I}$ & Sifat-sifat logaritma \\
\hline 4 & Grafik persamaan logaritma & DI & II & $\begin{array}{l}\text { Belum memahami notasi titik } \\
\text { koordinat }\end{array}$ \\
\hline 5 & $\begin{array}{l}\text { Persamaan logaritma berbentuk }{ }^{\text {alog }} \\
\qquad f(x)=p\end{array}$ & DA & II & $\begin{array}{c}\text { tidak memeriksa kembali } \\
\text { domain pada persamaan } \\
\text { logaritma }\end{array}$ \\
\hline 7 & $\begin{array}{l}\text { Persamaan logaritma berbentuk }{ }^{\mathrm{h}(\mathrm{x})} \log \\
\mathrm{f}(\mathrm{x})={ }^{\mathrm{h}(\mathrm{x})} \log \mathrm{g}(\mathrm{x})\end{array}$ & DA & II & $\begin{array}{l}\text { tidak memeriksa kembali } \\
\text { domain pada persamaan } \\
\text { logaritma }\end{array}$ \\
\hline 10 & Aplikasi logaritma dalam kehidupan & DA & II & Sifat-sifat logaritma \\
\hline
\end{tabular}

Berdasarkan Tabel 8, miskonsepsi siswa terdapat pada nomor 4, 6, 7, dan 10 untuk tes I, sedangkan miskonsepsi siswa pada nomor 4, 5, 7, dan 10 untuk tes II. Sehingga, berdasarkan triangulasi metode tes I dan tes II pada Tabel 4.20, miskonsepsi siswa terdapat pada nomor 4, 7, dan 10. Miskonsepsi siswa pada nomor 4 dengan indikator soal disajikan persamaan logaritma, siswa diminta untuk membuat grafik dari persamaan logaritma tersebut pada sub 
konsep grafik persamaan logaritma dengan letak miskonsepsi belum memahami notasi titik koordinat. Miskonsepsi siswa pada nomor 7 dengan indikator soal disajikan persamaan logaritma, peserta didik dapat menentukan himpunan persamaan logaritma yang berbentuk ${ }^{h(x)} \log f(x)={ }^{h(x)} \log g(x)$ pada sub konsep persamaan logaritma berbentuk ${ }^{h(x)} \log f(x)={ }^{h(x)} \log$ $\mathrm{g}(\mathrm{x})$ dengan letak miskonsepsi sifat-sfat logaritma dan tidak memeriksa kembali domain pada persamaan logaritma. Miskonsepsi siswa pada nomor 10 dengan indikator soal disajikan soal aplikasi logaritma, siswa diminta untuk menentukan nilai dari soal yang ditanyakan terletak pada sub konsep aplikasi logaritma dalam kehidupan dengan letak miskonsepsi sifat-sifat logaritma.

Pada subkonsep persamaan grafik logaritma, subjek selalu mensubstitusikan titik-titik yang diketahui tanpa menggunakan sketsa grafik maupun perhitungan dengan benar. Pada subkonsep $^{\mathrm{h}(\mathrm{x})} \log \mathrm{f}(\mathrm{x})={ }^{\mathrm{h}(\mathrm{x})} \log \mathrm{g}(\mathrm{x})$, subjek tidak memeriksa kembali nilai $\mathrm{x}$ yang diperoleh ke dalam persamaan soal sehingga dihasilkan nilai $x$ yang benar. Hal tersebut sesuai dengan pendapat Allen (2007) bahwa miskonsepsi siswa terjadi pada persamaan logaritma dengan indikator siswa tidak memeriksa kembali domain pada persamaan logaritma. Mensubstitusikan nilai x digunakan untuk memeriksa kembali domain pada persamaan logaritma. Subjek juga tidak menggunakan sifat-sifat logaritma dengan benar ketika melakukan penyelesaian soal. Pada subkonsep aplikasi logaritma dalam kehidupan, subjek mengalami kesalahan dalam menggunakan sifat-sifat logaritma. Hal ini sesuai dengan pendapat Liang \& Wood (2005) bahwa rendahnya kemampuan siswa yang menyebabkan miskonsepsi terjadi pada materi logaritma, yaitu pada menyelesaikan sifat-sifat logaritma.

Dari hasil wawancara dan analisis hasil jawaban siswa, siswa mengalami miskonsepsi pada nomor 4, 7, dan 10 dengan penyebab umum siswa dan cara mengajar. Penyebab miskonsepsi nomor 4 disebabkan karena siswa dengan sebab khusus karena penjelasan yang tidak lengkap/salah dan minat belajar. Penyebab miskonsepsi nomor 7 disebabkan karena siswa dengan sebab khusus prakonsepsi dan penjelasan yang tidak lengkap/salah. Penyebab miskonsepsi nomor 10 disebabkan karena siswa dan cara mengajar. Sebab khusus siswa karena prakonsepsi, penjelasan yang tidak lengkap/salah, dan minat belajar siswa. Sedangkan sebab khusus cara mengajar yang hanya berisi ceramah dan menulis.

Pada subkonsep persamaan grafik logaritma pada nomor 4, subjek mengalami miskonsepsi disebabkan oleh penjelasan yang salah atau tidak lengkap dan minat belajar yang rendah. Penyebab miskonsepsi siswa yang disebabkan karena penjelasan yang salah atau tidak lengkap yang ditunjukkan oleh subjek adalah subjek tidak menyebutkan syarat bentuk 
persamaan logaritma. Pernyataan tersebut seperti pendapat Suparno (dalam Agustianih, 2017) yang mengatakan bahwa penyebab miskonsepsi siswa karena siswa sendiri dengan sebab khusus karena penjelasan yang tidak lengkap/salah. Sedangkan penyebab miskonsepsi siswa yang disebabkan oleh minat belajar yang ditunjukkan oleh subjek menjelaskan bahwa subjek malas membaca materi. Suparno (dalam Agustianih, 2017) yang mengatakan bahwa sebab miskonsepsi karena siswa itu sendiri adalah salah satunya karena minat belajar siswa.

Pada subkonsep ${ }^{\mathrm{h}(\mathrm{x})} \log \mathrm{f}(\mathrm{x})={ }^{\mathrm{h}(\mathrm{x})} \log \mathrm{g}(\mathrm{x})$ pada nomor 7 , subjek mengalami miskonsepsi karena siswa itu sendiri dengan sebab khusus prakonsepsi dan penjelasan yang salah/tidak lengkap. Penyebab miskonsepsi siswa karena prakonsepsi ditunjukkan bahwa subjek mengatakan bahwa subjek juga tidak mempersiapkan materi sebelum menerima materi persamaan logaritma. Hal ini sesuai dengan isi angket yang dituliskan oleh Kurniasih \& Haka (2017) "Saya selalu mempersiapkan materi atau bahan pelajaran yang akan dibahas satu hari sebelum materi tersebut diajarkan" tentang sebab khusus prakonsepsi siswa. Penyebab miskonsepsi siswa karena penjelasan yang salah ditunjukkan bahwa subjek menjelaskan jawaban dengan penjelasan yang salah tentang sifat logaritma. Pernyataan tersebut seperti pendapat Suparno (dalam Agustianih, 2017) yang mengatakan bahwa penyebab miskonsepsi siswa karena siswa sendiri dengan sebab khusus karena penjelasan yang tidak lengkap/salah.

Pada subkonsep aplikasi logaritma dalam kehidupan pada nomor 10, subjek mengalami miskonsepsi karena siswa itu sendiri dengan sebab khusus prakonsepsi, penjelasan yang salah/tidak lengkap, dan minat belajar siswa, serta karena cara mengajar. Penyebab khusus miskonsepsi siswa adalah karena prekonsepsi siswa penjelasan yang salah. Penyebab miskonsepsi siswa karena prakonsepsi ditunjukkan bahwa subjek mengatakan bahwa subjek juga tidak mempersiapkan materi sebelum menerima materi persamaan logaritma. Hal ini sesuai dengan isi angket yang dituliskan oleh Kurniasih \& Haka (2017) "Saya selalu mempersiapkan materi atau bahan pelajaran yang akan dibahas satu hari sebelum materi tersebut diajarkan" tentang sebab khusus prakonsepsi siswa. Penyebab miskonsepsi siswa karena penjelasan yang salah ditunjukkan bahwa subjek menjelaskan jawaban dengan penjelasan yang salah tentang sifat logaritma. Suparno (dalam Agustianih, 2017) yang mengatakan bahwa penyebab miskonsepsi siswa karena siswa sendiri dengan sebab khusus karena penjelasan yang tidak lengkap/salah. Sedangkan miskonsepsi siswa karena minat belajar ditunjukkan bahwa subjek tidak menyiapkan materi sebelum mendapatkan materi persamaan logaritma. Sebab khusus miskonsepsi siswa karena cara mengajar ditunjukkan bahwa subjek mengalami miskonsepsi karena cara mengajar yang diajarkan guru hanya berisi ceramah dan 
menulis. Hal ini sesuai dengan pendapat Suparno (Agustianih, 2017) yang mengatakan bahwa yang mengatakan bahwa sebab miskonsepsi karena cara mengajar adalah karena pembelajaran yang hanya berisi ceramah dan menulis.

Tabel 9 Pengelompokan Penyebab Miskonsepsi Siswa

\begin{tabular}{ccccc}
\hline No & Jenis Tes & Nomor Soal & \multicolumn{2}{c}{ Penyebab } \\
\cline { 3 - 4 } & & Umum & Khusus \\
\hline 1 & I dan II & 4 & Siswa & $\begin{array}{c}\text { Penjelasan yang Tidak Lengkap/Salah dan } \\
\text { Minat Belajar }\end{array}$ \\
\hline 2 & I dan II & 7 & Siswa & $\begin{array}{c}\text { Prakonsepsi dan Penjelasan yang Tidak } \\
\text { Lengkap/Salah }\end{array}$ \\
\hline 3 & I dan II & 10 & Cara Mengajar & Hanya Berisi Ceramah dan Menulis \\
\cline { 3 - 4 } & & Siswa & $\begin{array}{c}\text { Prakonsepsi, Penjelasan yang Tidak } \\
\text { Lengkap/Salah, dan Minat Belajar }\end{array}$ \\
\hline
\end{tabular}

Sedangkan untuk penyebab miskonsepsi siswa materi persamaan logaritma berdasarkan angket, didapatkan bahwa penyebab utama miskonsepsi pada siswa adalah karena Siswa dan konteks. Sebab khusus miskonsepsi siswa karena konteks dengan persentase tertinggi adalah teman diskusi yang salah, perasaan senang/tidak senang; beban atau terkekang, bahasa seharihari berbeda. Sebab khusus miskonsepsi siswa karena siswa dengan persentase tertinggi pernyataan negatif yaitu prakonsepsi, kemampuan siswa, dan minat belajar.

Alternatif:

Miskonsepsi siswa berdasarkan penjelasan di atas dapat disebabkan oleh siswa itu sendiri karena sebab khusus yang berupa kemampuan siswa, prakonsepsi, dan minat belajar. Penyebab khusus karena kemampuan siswa menjadi faktor mendominan dari faktor khusus lainnya. Berdasarkan pembahasan di atas, sebanyak 7 subjek yang mengalami miskonsepsi karena kemampuan mereka.

Alternatif penyelesaian untuk siswa yang mengalami miskonsepsi dengan sebab khusus prakonsepsi menurut Yahya \& Ekawati (2016) adalah dengan memberikan penjelasan ulang tentang konsep sebanding. Memberikan contoh atau noncontoh pada konsep materi persamaan logaritma pada bentuk soal yang mengalami miskonsepsi; memberikan suatu permasalahan persamaan logaritma lagi dan memberikan contoh penyelesaian yang benar; memberikan diskusi perubahan konsep-konsep yang berhubungan dengan permasalahan materi persamaan logaritma, dan juga pemberian contoh dan noncontoh.

Alternatif penyelesaian untuk siswa yang mengalami miskonsepsi dengan sebab khusus penjelasan yang salah/tidak lengkap menurut Yahya \& Ekawati (2016) adalah dengan memberikan penjelasan ulang yang telah benar tentang materi persamaan logaritma; menjelaskan ulang kepada subjek mengenai konsep tentang strategi yang benar yang dapat diaplikasikan untuk menyelesaikan masalah yang diberikan; memberikan contoh atau non 
contoh, yaitu dengan memberikan contoh ataupun non contoh materi persamaan logaritma; dan menjelaskan agar tidak hanya menuliskan ataupun hanya menjawab saja tanpa memperhatikan konteks permasalahan yang diberikan pada soal.

Alternatif penyelesaian untuk siswa yang mengalami miskonsepsi dengan sebab khusus minat belajar menurut Anggraeni (2017) adalah memberikan kesempatan kepada siswa untuk memilih jenis tes apa yang diharapkan atau juga materi jenis apa yang ingin dipelajari saat pembelajaran; sebisa mungkin guru untuk memberikan instruksi, peraturan dan harapan kepada siswa secara jelas agar kedepannya siswa faham dengan maksud dan tujuan gurunya; memberikan motivasi dengan memberikan kepercayaan kepada siswa; untuk meningkatkan ketertarikan siswa dalam mempelajari suatu materi, guru memberikan kesempatan kepada siswa untuk belajar di luar kelas; sebisa mungkin guru dalam menerapkan model atau metode pembelajaran yang bervariasi, ini akan mengurangi kejenuhan siswa saat pembelajaran; menciptakan suasana kelas agar bisa menumbuhkan persaingan positif, mungkin bisa melalui permainan kelompok yang terkait dengan materi atau suatu kesempatan yang bisa memamerkan pengetahuan mereka (BSE, 2012); menawarkan hadiah kepada siswa jika mereka berhasil melakukan sesuatu merupakan salah satu cara jitu untuk meningkatkan motivasi belajar (Mulyati, 2016); menugaskan siswa sebuah pekerjaan kelas adalah cara yang bagus untuk membangun komunitas dan untuk memberikan siswa rasa motivasi; memberikan kesempatan kepada siswa untuk belajar secara berkelompok; mendorong siswa untuk memotivasi atau merefleksi diri siswa; memperlihatkan semangat saat mengajar; mengenal siswa; mengetahui minat siswa; membantu siswa untuk menemukan motivasi dari dalam dirinya; mengelola kecemasan siswa; membuat tujuan yang tinggi tetapi masih bisa dicapai siswa; memberikan umpan balik dan membantu menemukan solusi dari suatu permasalahan; membuat track progress sebagai cara untuk memotivasi siswa, yang memungkinkan mereka untuk melihat secara visual seberapa jauh prestasi belajar mereka sepanjang tahun; dan menambahkan sebuah kegiatan yang menyenangkan di kelas bisa membantu siswa yang kesulitan untuk tetap terlibat dan akan membuat kelas menjadi tempat yang jauh lebih ramah untuk semua siswa; memastikan bahwa semua siswa mendapatkan kesempatan untuk terlibat dalam suatu kegiatan pembelajaran, sehingga akan meningkatkan motivasi dari dalam diri mereka untuk melakukan yang terbaik.

Miskonsepsi siswa berdasarkan penjelasan di atas dapat disebabkan oleh cara mengajar karena sebab khusus yang berupa cara mengajar yang yang hanya berisi ceramah dan menulis. Guru perlu mempersiapkan strategi pembelajaran yang baik agar pembelajaran menjadi 
bermakna sehingga pemahaman konsep siswa akan meningkat (Agustianih, 2017). Maka dari itu, diperlukan pembelajaran yang maksimal agar miskonsepsi dapat diperkecil.

Menurut Fadllan (2011) Untuk mengatasi miskonsepsi mahasiswa tersebut, salah satu model pembelajaran yang dapat diterapkan adalah Model Pembelajaran Konflik Kognitif, yakni model pembelajaran di mana mahasiswa dihadapkan pada pertentangan antara prakonsepsi yang telah dimiliki dengan konsep ilmiah yang sebenarnya, sehingga mahasiswa akan menyadari kekeliruannya dan mengubah atau melengkapi konsep yang dipahaminya. Jadi, salah satu pembelajar yang bisa mencegah dan menanggulangi miskonsepsi adalah menggunakan Model Pembelajaran Konflik Kognitif. Pembelajaran ini bisa mencegah dan menanggulangi miskonsepsi akibat penyebab miskonsepsi seperti prakonsepsi kemampuan siswa selama pembelajaran. Seperti yang dijelaskan oleh Fadllan (2011) bahwa Model ini terdiri atas tiga fase: (1) mengidentifi kasi miskonsepsi beserta latar penyebabnya;(2) mengonfrontasikan gagasan mahasiswa (prakonsepsi) dengan konsepsi ilmiah, dalam upaya menggoyahkan miskonsepsi mahasiswa dan agar mahasiswa menjadi ragu terhadap kebenaran prakonsepsinya; (3) fase konflik, di mana mahasiswa menjadi mengerti dan mau mereorganisasi serta merestrukturisasi gagasannya yang megalami miskonsepsi.

\section{Simpulan dan Saran}

Miskonsepsi yang dialami oleh siswa pada materi persamaan logaritma menggunakan tes diagnostik Two-Tier dan Three Tier Multiple Choice yaitu miskonsepsi pada nomor 4, 7, dan 10 dengan subkonsep berturut-turut yaitu pada grafik persamaan logaritma, persamaan logaritma berbentuk ${ }^{\mathrm{h}(\mathrm{x})} \log \mathrm{f}(\mathrm{x})={ }^{\mathrm{h}(\mathrm{x})} \log \mathrm{g}(\mathrm{x})$, dan aplikasi logaritma dalam kehidupan.

Penyebab miskonsepsi siswa materi persamaan logaritma berdasarkan angket, didapatkan bahwa penyebab utama miskonsepsi pada siswa adalah karena Siswa dan konteks. Sebab khusus miskonsepsi siswa karena konteks dengan persentase tertinggi adalah teman diskusi yang salah, perasaan senang/tidak senang; beban atau terkekang, bahasa sehari-hari berbeda. Sebab khusus miskonsepsi siswa karena siswa dengan persentase tertinggi pernyataan negatif yaitu prakonsepsi, kemampuan siswa, dan minat belajar.

Alternatif penyelesaian menanggulangi miskonsepsi siswa SMA pada materi logaritma dibedakan menjadi dua yaitu alternatif penyelesaian menanggulangi miskonsepsi karena siswa dan cara mengajar. Salah satu alternatif penyelesaian menanggulangi miskonsepsi karena siswa itu sendiri dengan cara guru perlu mengerti sejauh mana konsep siswa ini tidak lengkap dan pelan-pelan dibantu dengan menambahkan bagian konsep yang kurang, dilakukan 
pembelajaran remediasi setelah teridentifikasi konsep alternatif siswa agar konsep yang salah dapat tereduksi. Salah satu alternatif penyelesaian menanggulangi miskonsepsi karena cara mengajar dengan cara guru perlu mempersiapkan strategi pembelajaran yang baik agar pembelajaran menjadi bermakna sehingga pemahaman konsep siswa akan meningkat. Maka dari itu, diperlukan pembelajaran yang efektif agar miskonsepsi dapat diperkecil.

\section{Referensi}

Agustianih, N. A., 2017. Analisis Miskonsepsi Siswa dengan Tes Diagnostik Two-Tier Multiple Choice pada Materi Hidrokarbon, Jakarta: Tidak Diterbitkan.

Allen, G. D., 2007. Misconception in Mathematics, Texas: Tidak Diterbitkan.

Anggraeni, 2017. Upaya Meningkatkan Minat Belajar Siswa pada Pembelajaran di Sekolah Dasar.

Astuti, F., Redjeki, T. \& Nurhayati, N. D., 2016. Identifikasi Miskonsepsi dan Penyebabnya Pada Siswa Kelas XI MIA SMA Negeri 1 Sukoharjo Tahun Pelajaran 2015/2016 pada Materi Pokok Stoikiometri. Jurnal Pendidikan Kimia (JPK), Volume 5, pp. 10-17.

Allen,BSE, 2012. Latar Belakang Pengadaan Buku Sekolah Elektronik. Jakarta: Pusat Buku Sekolah Elektronik.

Ekasari, N. A., 2015. Analisis Kesalahan Siswa Kelas X dalam Menyelesaikan Soal Matematika Pada Materi Logaritma Berdasarkan Prosedur Newman, Ponorogo: Tidak Diterbitkan.

Fadllan, A., 2011. Model Pembelajaran Konflik Kognitif untuk Mengatasi Miskonsepsi pada Mahasiswa Tadris Fisika Program Kualifikasi S.1 Guru Madrasah. Phenomenon, Volume 2, pp. 139-159.

Fatqurhohman, 2016. Pemahaman Konsep Matematika Siswa dalam Menyelesaikan Bangun Datar. Jurnal Ilmiah Pendidikan Matematika, Volume 4, pp. 127-133.

Fitria, A., 2014. Miskonsepsi Mahasiswa dalam Menentukan Grup pada Struktur Aljabar Menggunakan Certainty Of Response Index (CRI) di Jurusan Pendidikan Matematika IAIN Antasari. JPM IAIN Antasari, Volume 1, pp. 45-60.

Kaltakçı, D. \& Nilüfer, D., 2007. Identification of Pre-Service Physics Teacher's Misconceptions on Gravity Concept. Turkey, American Institute of Physics.

Kurniasih, N. \& Haka, N. B., 2017. Penggunaan Tes Diagnostik Two-Tier Multiple Choice untuk Menganalisis Miskonsepsi Siswa Kelas X pada Materi Archaebacteria dan Eubacteria. Jurnal Tadris Pendidikan Biologi, Volume 8, pp. 114-127.

Leinhardt, G., Zaslavsky, O. \& Stein, M. K., 1990. Functions, Graphs, and Graphing: Task, Learning, and Teaching. Review of Educational Research, Volume 60, pp. 1-64.

Liang, C. B. \& Wood, E., 2005. Working with Logarithms: Students' misconceptions and Errors. The Mathematics Educator, Volume 8, pp. 53-70.

Mulyati, T., 2016. Kemampuan Pemecahan Masalah Matematis Siswa Sekolah Dasar. EduHumaniora, Volume 3. 
Muna, I. A., 2015. Identifikasi Miskonsepsi Mahasiswa PGMI pada Konsep Hukum Newton Menggunakan Certainty of Response Index (CRI). Cendekia, Volume 13, pp. 309-322.

Murizal, A., Yarman \& Yerizon, 2012. Pemahaman Konsep Matematis dan Model Pembelajaran Quantum Teaching. Jurnal Pendidikan Matematika, Volume 1, pp. 19-23.

Susanti, D., Waskito, S. \& Surantoro, 2014. Penyusunan Instrumen Tes Diagnostik Miskonsepsi Fisika SMA Kelas XI pada Materi Usaha dan Energi. Jurnal Pendidikan Fisika, Volume 2, pp. 16-19.

Suwarto, 2013. Model-model Instrumen Diagnostik. Widyatama, Volume 22, pp. 64-70.

Suwarto, 2013. Pengembangan Tes Dagnostik dalam Pembelajaran. Yogyakarta: Pustaka Pelajar.

Utari, V., Fauzan, A. \& Rosha, M., 2012. Peningkatan Kemampuan Pemahaman Konsep Melalui Pendekatan PMRdalam Pokok Bahasan Prisma dan Limas. Jurnal Pendidikan Matematika, Volume 1, pp. 33-38.

Wafiyah, N., 2012. Identifikasi Miskonsepsi Siswa dan Faktor-Faktor Penyebab pada Materi Permutasi dan Kombinasi di SMA Negeri 1 Manyar. Gamatika, Volume 2, pp. 128-138.

Yahya, M. I., 2016. Analisis Miskonsepsi Siswa Kelas VIII Pada Materi Perbandingan dan Proporsi Serta Alternatif Penyelesaiannya. Mathedunesa, 3(2016), pp. 283-289. 